\title{
The effect of PCL to knee proprioception in TKA: A prospective study
}

GA Skarpas ${ }^{3,4}$, K Karzis ${ }^{2}$, Arhontoula Xifara ${ }^{3}$, Maria Zarokosta ${ }^{3}$, Menelaos Zoulamoglou ${ }^{3}$, Theodoros Piperos ${ }^{3}$, Theodoros MariolisSapsakos $^{3}$, IV Michos ${ }^{1}$ and K Kazakos ${ }^{5}$

14th Orthopaedic Department, General Hospital “Asklepieion Voulas”, Greece

${ }^{2}$ Department of Physiotherapy, General Hospital “Asklepieion Voulas”, Greece

${ }^{3}$ Anatomy, Histology \& Embryology Lab, University of Athens-Nursing Department, Greece

${ }^{4}$ University Hospital "Evgenideio”, Orthopaedic Department, Greece

${ }^{5}$ Orthopaedic Department, Medical School, University of Thrace, Greece

\section{Introduction}

The role of the posterior cruciate ligament (PCL) remains controversial in total knee arthroplasty (TKA). It is recognized that awareness of joint position in the knee deteriorates because of aging, anterior cruciate injury, or osteoarthritis [1]. Proprioception was studied after TKA, in both posterior cruciate ligament (PCL)-retaining and posterior stabilizing (PS) prosthetic designs. Soft-tissue release during total knee replacement may have an influence [2]. There is no consensus as to whether to use a posterior cruciate ligament (PCL) retaining design or a posterior-stabilized design for total knee arthroplasty [3] although the presence of mechanoreceptors is shown in histologic analysis to be maintained in CR TKA(4). The presence or retention of mechanoreceptors and innervations of the ligament may indicate an advantage when retained during TKA and is beneficial in stability and function [4]. The objective of this study is to establish the difference in functional, clinical, and radiological outcome between retention and removal of the PCL. Range of motion after a total knee arthroplasty is an important indicator of clinical outcome [5] promoted by proprioception maintainance.

\section{Material and method}

In a clinical prospective study, proprioception was measured in two groups of patients following successful total knee arthroplasty (TKA). In one group (15 pts), the posterior cruciate ligament was retained and an unconstrained cruciate-retaining total knee component was used; in the other group ( $15 \mathrm{pts})$, the posterior cruciate ligament was excised and a cruciate-substituting design was implanted. All measurements obtained with the use of the electronic dynamometer Con-Trex MJ (Con-Trex, Zurich, Switzerland). All pts followed a speciallized and supervised rehabilitation programm. For the proprioceptive assessment, reproduction of joint position (JPS) in predetermined angles $\left(30^{\circ} \mathrm{Kal} 60^{\circ}\right)$ as well as sense of joint movement (SJM) were measured, together with threshold to detection of passive motion in flexion and extension (TTDPM). Also concentric quadriceps and hamstrings strength at $30 \% \mathrm{sec}$ and $60 \% \mathrm{sec}$ was evaluated. The degree of preoperative arthritis was objectively classified according to Resnick and Niwoyama. Each patient completed a self-administered, validated Total Knee Function Questionnaire (TKFQ) as well as the SF-36. Knee functional capacity was evaluated with the use of KSSTA/IKDC scores. The statistical analysis was performed using T-test for independent samples. The statistical level was set at $\mathrm{p}<0.05 .20$ women and 10 men were evaluated, with knees being 21 right and 9 left, with a mean age of 73 y.o., mean height $167 \mathrm{~cm}$ and mean BMI 32 (61\% overweight). The isokinetic testing included: a) the bilateral peak torque production of quadriceps and hamstrings muscles, $b$ ) the bilateral average peak torque production, c) the bilateral Hamstring/Quadricep ratio (H/Q), d) the bilateral time to peak torgue of quadriceps muscle. Isokinetic testing was performed on the operative and nonoperative legs at $30 \&$ 60 degrees/sec before surgery and at 3 and 6 months postoperatively. ANOVA with repeated measures were conducted in order to determine any differences in the the muscle force production between the operated and contralateral healthy knee before surgery and at 3 and 6 months postoperatively. A $P$-value of $<0.05$ was considered statistically significant. The procedure included isokinetic measurements during movement from full extension to $90^{\circ}$ flexion, at angular velocities $30 \% \mathrm{sec}$ and $60 \% \mathrm{sec}$, in both operated and healthy leg. The values of concentric peak torque for flexion (PTF), and for extension (PTE), were recorded at the angular velocities of $30 \% \mathrm{sec}$ and $60 \% \mathrm{sec}$, at both legs. The Limb Symmetry Index, (LSI), for flexion and extension was calculated: in all patients the Hamstrings to Quadriceps ratio, (H/Q), at angular velocities $30^{\circ} / \mathrm{sec}$ and $60 \% \mathrm{sec}$, and compared it to the healthy side, concluding to the Limb Symmetry Index (LSI). Statistical analysis with mean scores and student's T- tests: A $P$-value of $<0.05$ was considered statistically significant.

\section{Results}

Overall there was a statistically significant difference, (t-test, $\mathrm{P}<0.05$ ) at $30^{\circ}$ and $60^{\circ}$ prior to, and 6 months after operation concerning JPS. Also for and SJM and TTDPM there was statistically significant difference at $30^{\circ}$, for flexion and extension, between pre- and 6 months post-operative findings.

At 3 months post-op, no statistically significant differences were detected between the 2 groups in all proprioceptive tests of function following total knee replacement, including overall satisfaction with

Correspondence to: GA Skarpas $\mathrm{MD}$, $\mathrm{PhD}$, Consultant Orthopaedic Surgeon/Lecturer of Anatomy, University of Athens, School of Nursing, 20 Papadiamandopoulou Str., Athens, Greece, Tel: +30210720810; +306942465650; E-mail: skarpasg@hotmail.com

Received: October 27, 2017; Accepted: November 20, 2017; Published: November 24, 2017 
operation. However, the TKFQ revealed that patients with PS knees reported greater functional limitations in squatting, kneeling, and gardening. Better stair climbing ability was attributed to cruciate retaining knees.

Also they demonstrated quicker recovery of sense of joint movement and significantly lower threshold to detection of passive motion in flexion mainly as well as wider ROM.

In patients with a moderate grade of arthritis before surgery, the postoperative scores were virtually identical [6]. When the grade of preoperative arthritis was severe, patients with cruciate-retaining TKAs performed significantly better than those with PS-TKAs.

At 6 months post-op., there was statistically significant difference for JPS at $60^{\circ}$ and no significant diference found at $30^{\circ}$ whereas in TTDPM in flexion and extension and SJM there was significant difference in both angles.

Concerning the Concentric Flexion torque: No statistically significant differences were detected between the operated and contra lateral healthy knee for hamstrings peak torque at 3 and 6 months postoperatively $(\mathrm{p}<0.05)$ in two isokinetic velocities and also there was no significant difference between the 2 groups. At angular velocity $30 \%$ $\mathrm{sec}$, the values for flexion muscle torque, (PTF), ranged from 43.5 $\mathrm{Nm}$ to $168,4 \mathrm{Nm}$ (av.106.6 Nm), but in the uninjured leg $48.6 \mathrm{Nm}$ to $170.7 \mathrm{Nm}$ (av. 110,8). At angular velocity $60 \% \mathrm{sec}$, the values ranged from $42,4 \mathrm{Nm}$ to $165,2 \mathrm{Nm}$ (av.104,3), while in the healthy side from 44.5 to $167.3 \mathrm{Nm}$ (av. 108,1). As for Concentric Extension torque: Isokinetic testing showed normal quadriceps peak torques at 3 and 6 months postoperatively. At $30 \% \mathrm{sec}$, the values for Knee extension torque varied from $45 \mathrm{Nm}$ to $282.7 \mathrm{Nm}$ (av. 187.2) for the operated side and from $52 \mathrm{Nm}$ to $293.6 \mathrm{Nm}$ (av. 197.3) for the uninjured side. At $60^{\circ} / \mathrm{sec}$, the values ranged from $43.5 \mathrm{Nm}$ to $279 \mathrm{Nm}$, (av.182,1Nm) for the operated side and from $50 \mathrm{Nm}$ to $284.7 \mathrm{Nm}$ (av. 186.9) for the healthy side. Average torque, across the full range of motion, and peak torque expressed in newton meters were divided by body weight in kilograms to produce torque values adjusted by body weight $[7,8]$, the males' weight-adjusted torque values were significantly (P less than $0.01)$ greater than the females.

The Hamstrings / Quadriceps, (H/Q) ratio (confidence in the knee), was calculated by dividing the Hamstrings over the Quadriceps value. In the operated side, the H/Q ratio ranged from 0,55 to 0,69 (av. 0,64 ), while the $H / Q$ ratio in the normal side was 0.69 to 0.82 (av.0.77). The Limb Symmetry Index (LSI), was calculated by dividing the values of the injured leg over the values of the uninjured leg and multiplying by 100 ; for extension torque ranged from $84,3 \%$ to $95.8 \%$ (av.92.3\%). LSI for extension $>90 \%$, was seen in 22 patients, $(73 \%)$. The Limb symmetry index for flexion torque ranged from $80,2 \%$ to $94,6 \%$ (av. $84,8 \%$ ). LSI for flexion $>90 \%$, was seen in 16 patients, (53\%). LSI over $90 \%$ is regarded the limit for normal function during weekender sport activities.

\section{Discussion}

In general knee proprioception in middle-aged and elderly persons with advanced knee arthritis is reduced [1]. For evaluating changes in proprioception after knee arthroplasty, it is best to compare the knee with the patient's untreated knee rather than with age-matched controls [1]. And in order to compare different prosthesis designs special proprioception tests should be performed [6]. Cadaver studies [9] have shown the effects of posterior cruciate ligament retention and sacrifice and the amount of deformity correction (with medial and lateral structure release) and thus functional outcome after TKA. With retention of the posterior cruciate ligament, less change was seen with both medial and lateral release and greater opening of the flexion gap was observed on the release side of the joint except those with sacrifice of the posterior cruciate ligament [9]. There were models of kinematic analysis of PCL retaining mobile-bearing total knee arthroplasty by using video fluoroscopy that were significantly in favor CR-TKA [10]. In addition to that other studies show significantly less motion alteration with retention of the posterior cruciate ligament with both medial and lateral release and more opening of the flexion gap was seen on the release side of the joint for all pts except those with lateral release and sacrifice of the posterior cruciate ligament [11] and when flexion gap tightness occurs, posterior cruciate ligament balancing is a useful aid, leading to better clinical outcome [12]. Technically when performing a cruciate-retaining knee, the key points are to avoid stiffness due to an extra tight flexion space caused by a tight PCL and to avoid flexion instability from over release of the PCL [13]. The ligament is virtually always intact and functioning, even in patients with rheumatoid arthritis [14]. Plays the important role of biologic stabilizer, absorbs anterior-posterior shearing forces that otherwise must be borne by a constrained prosthesis and through this, by the bone-cement interface [14]. Keeping PCL intact or with moderate release, allows maintenance of the normal kinematics of the knee: roll-back of the femur on the tibia can occur, enhancing flexion and improving the quadriceps function and strength [14]. The issue of survival of the implants is also in favor of CR-TKA together with age, sex, diagnosis, and deformity effects [15]. Even in studies with no statistically significant differences between the 2 groups during 1 year follow-up, there was a great difference at the TKFQ, which revealed that patients with PS-TKA reported greater functional limitations in squatting, kneeling, and gardening (16). On top of this the PS models seem to be unable to imitate the functional capacity of PCL particularly in high-demand activities that involve deep flexion, and thus leading to motion limitation [16]. It should be stressed that choosing PCL retention is a demanding technique, because the normal configuration and tension need to be reproduced with ligament tensioners and all the appropriate outcome parameters such as ROM, contact position and anteroposterior stability have to be encountered [17]. Evidence concerning the prosthetic design have shown that PCL-retaining implants contribute to a greater improvement in proprioception, than PS models [18]. Finally, many researchers have suggested serious complications of PS-TKA, one of them being the most painful and demanding, the synovial entrapment that can lead to severe motion limitations [19]. In our study, the significant difference between the 2 groups after 3 and 6 months follow-up, concerns ROM, functional outcome and recovery of strenght and kinaesthesia, all in favor of the CR-TKA group. In comparison to other studies that used similar methods to measure the proprioception pre and post-op, and found no significant differencies in TTDPM and also corellation of post-op performance with preoperative arthritis [6], we feel that we assesssed all possible outcome parameters in an unbiased and detailed manner within the current scientific limitations. Even with our results, the discussion is still open and it is inevitable that further follow-up and investigation is needed, in order to reach a consensus on this importaant issue.

\section{Conflict of interest statement}

None.

\section{Funding}

There is no source of funding. 


\section{Consent}

Written consent was provided from the patients for the publication of the case series and accompanying images.

\section{References}

1. Koralewicz LM, Engh GA (2000) Comparison of proprioception in arthritic and agematched normal knees. J Bone Joint Surg Am 82-82A: 1582-8. [Crossref]

2. Attfield SF, Wilton TJ, Pratt DJ, Sambatakakis A (1996) Soft-tissue balance and recovery of proprioception after total knee replacement. J Bone Joint Surg Br 78: 540545. [Crossref]

3. Jacobs WC, Clement DJ, Wymenga AB (2005) Retention versus removal of the posterior cruciate ligament in total knee replacement: a systematic literature review within the Cochrane framework. Acta Orthop 76: 757-768. [Crossref]

4. Mihalko WM, Creek AT, Mary MN, Williams JL, Komatsu DE (2011) Mechanoreceptors found in a posterior cruciate ligament from a well-functioning total knee arthroplasty retrieval. $J$ Arthroplasty 26: 504. [Crossref]

5. Seon JK, Park SJ, Lee KB, Yoon TR, Kozanek M, et al. (2009) Range of motion in total knee arthroplasty: a prospective comparison of high-flexion and standard cruciateretaining designs. J Bone Joint Surg Am 91: 672-679. [Crossref]

6. Simmons S1, Lephart S, Rubash H, Borsa P, Barrack RL (1996) Proprioception following total knee arthroplasty with and without the posterior cruciate ligament. $J$ Arthroplasty 11: 763-768. [Crossref]

7. Highgenboten CL, Jackson AW, Meske NB (1988) Concentric and eccentric torque comparisons for knee extension and flexion in young adult males and females using the Kinetic Communicator. Am J Sports Med 16: 234-7. [Crossref]

8. Çakır T, Toraman NF, Uçkun A, Yalçın Ü (2016) Isokinetic exercise improves concentric knee flexion torque better than isometric exercise in patients with advanced osteoarthritis. Isokinetics and Exercise Science 24: 7-15.
9. Mihalko WM, Miller C, Krackow KA (2000) Total knee arthroplasty ligament balancing and gap kinematics with posterior cruciate ligament retention and sacrifice. Am J Orthop (Belle Mead NJ) 29: 610-616. [Crossref]

10. Oakeshott R, Stiehl JB, Komistek RA, Anderson DT, Haas BD (2003) Kinematic analysis of a posterior cruciate retaining mobile-bearing total knee arthroplasty. $J$ Arthroplasty 18: 1029-1037. [Crossref]

11. Mihalko WM, Miller C, Krackow KA (2000) Total knee arthroplasty ligament balancing and gap kinematics with posterior cruciate ligament retention and sacrifice. Am J Orthop (Belle Mead NJ) 29: 610-616. [Crossref]

12. Ritter MA, Faris PM, Keating EM (1988) Posterior cruciate ligament balancing during total knee arthroplasty. J Arthroplasty 3: 323-326. [Crossref]

13. Sierra RJ, Berry DJ (2008) Surgical technique differences between posteriorsubstituting and cruciate-retaining total knee arthroplasty. J Arthroplasty 23: 20-3. [Crossref]

14. Scott RD, Volatile TB (1986) Twelve years' experience with posterior cruciateretaining total knee arthroplasty. Clin Orthop Relat Res 205: 100-107. [Crossref]

15. Abdel MP, Morrey ME, Jensen MR, Morrey BF (2011) Increased long-term survival of posterior cruciate-retaining versus posterior cruciate-stabilizing total knee replacements. J Bone Joint Surg Am 93: 2072-2078. [Crossref]

16. Conditt MA, Noble PC, Bertolusso R, Woody J, Parsley BS (2004) The PCL significantly affects the functional outcome of total knee arthroplasty. $J$ Arthroplasty 19: 107-112. [Crossref]

17. Jacobs WC, Clement DJ, Wymenga AB (2005) Retention versus sacrifice of the posterior cruciate ligament in total knee replacement for treatment of osteoarthritis and rheumatoid arthritis. Cochrane Database Syst Rev CD004803. [Crossref]

18. Warren PJ, Olanlokun TK, Cobb AG, Bentley G (1993) Proprioception after knee arthroplasty. The influence of prosthetic design. Clin Orthop Relat Res 182-187. [Crossref]

19. Pollock DC, Ammeen DJ, Engh GA (2002) Synovial entrapment: a complication of posterior stabilized total knee arthroplasty. J Bone Joint Surg Am 84-84A: 2174-8. [Crossref]

Copyright: (C2017 Skarpas GA. This is an open-access article distributed under the terms of the Creative Commons Attribution License, which permits unrestricted use, distribution, and reproduction in any medium, provided the original author and source are credited. 